Article

\title{
Hot Deformation Behavior and Microstructure Characterization of an Al-Cu-Li-Mg-Ag Alloy
}

\author{
Lingfei Cao ${ }^{1,2} \mathbb{D}$, Bin Liao $^{3}$, Xiaodong $\mathrm{Wu}^{1,2, * \mathbb{D}}$, Chaoyang $\mathrm{Li}^{1}{ }^{1}$, Guangjie Huang ${ }^{1}$ and \\ Nanpu Cheng ${ }^{4, *}$
}

1 International Joint Laboratory for Light Alloys (Ministry of Education), College of Materials Science and Engineering, Chongqing University, Chongqing 400044, China; caolingfei@cqu.edu.cn (L.C.); licy@cqu.edu.cn (C.L.); gjhuang@cqu.edu.cn (G.H.) Shenyang National Laboratory for Materials Science, Chongqing University, Chongqing 400044, China

Alnan Aluminium Co., Ltd., Nanning Guangxi 530031, China; bin.liao@foxmail.com

4 School of Materials and Energy, Southwest University, Chongqing 400715, China

* Correspondence: xiaodongwu@cqu.edu.cn (X.W.); cheng_np@swu.edu.cn (N.C.); Tel.: +86-23-65127306 (X.W.); +86-23-68253204 (N.C.)

Received: 19 April 2020; Accepted: 20 May 2020; Published: 22 May 2020

\begin{abstract}
The flow behavior of an Al-Cu-Li-Mg-Ag alloy was studied by thermal simulation tests at deformation temperatures between $350{ }^{\circ} \mathrm{C}$ and $470{ }^{\circ} \mathrm{C}$ and strain rates between $0.01-10 \mathrm{~s}^{-1}$. The microstructures of the deformed materials were characterized by electron backscattered diffraction. Constitutive equations were developed after considering compensation for strains. The processing maps were established and the optimum processing window was identified. The experimental data and predicted values of flow stresses were in a good agreement with each other. The influence of deformation temperature and strain rates on the microstructure were discussed. The relationship between the recrystallization mechanism and the Zener-Hollomon parameter was investigated as well.
\end{abstract}

Keywords: Al-Cu-Li-Mg-Ag alloy; constitutive equation; EBSD; recrystallization

\section{Introduction}

$\mathrm{Al}-\mathrm{Cu}-\mathrm{Li}$ alloys have great application potentials in the aerospace field due to their excellent properties, such as low density, high strength, and stiffness [1-3]. The addition of $1 \mathrm{wt} \% \mathrm{Li}$ in aluminum can approximately reduce its density for 3\% and enhance its elastic modulus for 6\% [4], which makes $\mathrm{Al}-\mathrm{Li}$ alloys suitable materials for lower wings and fuselages of airplanes. During the production, hot working on these alloys is generally unavoidable, in which the hot working temperature and strain rate are key parameters for quality control. The process design largely depends on a good understanding of the deformation mechanism. Therefore, it is necessary to investigate systematically the deformation behaviors and microstructure evolution at high temperatures for $\mathrm{Al}-\mathrm{Cu}-\mathrm{Li}$ alloys.

The thermal simulation technique has been an effective method to investigate the behaviors of materials under thermo-mechanical loading. Constitutive models can be developed subsequently to describe the relationship among deformation temperature, strain rate, and flow stress [5]. The flow behaviors of aluminum alloys have been widely simulated by Arrhenius type equations [6-10], which is helpful for process design in a specific deformation condition.

Thermal softening, which was a result of dynamic recovery (DRV) and dynamic recrystallization (DRX), and strain hardening have a close relationship with deformation conditions. An improper choice of deformation parameters may induce surface cracks, inhomogeneous distribution of grains, and flow localization. Therefore, processing maps have been established on the basis of power dissipation to 
avoid undesirable deformation conditions [11]. Yin [12] developed a processing map for an Al-Cu-Li alloy, where the suitable processing windows were set up at $450-500{ }^{\circ} \mathrm{C}$ and $0.01-0.1 \mathrm{~s}^{-1}$. Shen [13] investigated the recrystallization of alloy 2397 at $450-550^{\circ} \mathrm{C}$ with strain rates of $0.001-0.1 \mathrm{~s}^{-1}$. It was reported that the dynamical recrystallization (DRX) was controlled by a combination of deformation mechanisms, i.e., grain boundary bulging (BLG) in the original grains and the transformation of low-angle grain boundaries (LAGBs) into high-angle grain boundaries (HAGBs) in the recrystallized grains. Nayan [14] established a wider processing map for alloy 2195 and found DRX was the main softening mechanism in the alloy. Two suitable processing windows are located at temperatures between $400-450{ }^{\circ} \mathrm{C}$ with strain rates of $10^{-2}-10^{-1.5} \mathrm{~s}^{-1}$ and $10^{-0.5}-10 \mathrm{~s}^{-1}$. Yu et al. studied the recrystallization in 2A97 alloy and found dynamic precipitation of $\mathrm{T}_{1}$ phase during hot deformation, and the main recrystallization mechanism was discontinuous dynamic recrystallization (DDRX) [7]. Ou et al.'s [15] study on alloy 2060 indicated that the dominant softening mechanism was DRV and the best hot working window for this alloy was a temperature of $380-500{ }^{\circ} \mathrm{C}$ and strain rates of $0.01-3 \mathrm{~s}^{-1}$.

It can be summarized that a different softening mechanism was proposed to explain the hot deformation behavior in $\mathrm{Al}-\mathrm{Cu}-\mathrm{Li}$ alloys, and various process maps were developed for suitable hot working windows. However, systematic investigations on the flow behavior, microstructure evolution, and deformation mechanism of 2060-type alloys are still needed, particularly on the deformation at typical production temperatures, strain rates and large strains. The related recrystallization mechanism is seldom reported as well. Therefore, in this work the hot compression tests on an Al-Cu- $\mathrm{Li}-\mathrm{Mg}-\mathrm{Ag}$ alloy were carried out to acquire the stress-strain data in near practical production conditions. The constitutive models were established and the processing maps were developed to investigate the flow behavior. The microstructure was characterized by using the electron back-scattered diffraction (EBSD) technique, and the relationship between $\ln Z$ and the recrystallization mechanism was discussed in detail.

\section{Materials and Methods}

The nominal composition of the experimental alloy was Al-4.0Cu-0.7Li-0.7Mg- $0.4 \mathrm{Zn}-0.3 \mathrm{Mn}-$ $0.3 \mathrm{Ag}-0.11 \mathrm{Zr}(\mathrm{wt} \%)$. The material was semi-continuously cast and homogenized at $410{ }^{\circ} \mathrm{C}$ for $4 \mathrm{~h}$ followed by $490^{\circ} \mathrm{C}$ for $24 \mathrm{~h}$, and then was machined into cylinders with a diameter of $8 \mathrm{~mm}$ and a height of $12 \mathrm{~mm}$ for hot compression tests.

A Gleeble 3500 thermo-mechanical tester (Dynamic Systems Inc., Austin, TX, USA) was used for the hot compression tests. The test temperatures were between $350{ }^{\circ} \mathrm{C}$ and $470{ }^{\circ} \mathrm{C}$ and the test strain rate was between 0.01 and $10 \mathrm{~s}^{-1}$. In order to ensure the reliability of data through hot compression tests, graphite was applied between the sample and the die to reduce the interface friction. The specimens were heated up with a heating rate of $2.5^{\circ} \mathrm{C} / \mathrm{s}$ and held for $3 \mathrm{~min}$ at the deformation temperature before the hot compression test to ensure a uniform temperature over the entire specimen, then were compressed to a reduction of $60 \%$ in thickness, and finally were quenched into water to reserve the hot deformation microstructures. The microstructures of the test specimens were characterized by a field emission scanning electron microscope (SEM, TESCAN MIRI 3, Brno, Czech Republic) with an electron backscatter diffraction (EBSD) detector (EDAX Inc., Oxford Instruments, Abingdon, UK).

The deformed samples were cut parallel to the compression direction. The examined surface was ground with different sizes of $\mathrm{SiC}$ papers and then electro-polished in an electrolyte solution comprised of $10 \%$ perchloric acid and $90 \%$ alcohol at $20 \mathrm{~V}$ for $15 \mathrm{~s}$ before observation. After exporting the data in the format cpr from AZtec software (version 3.2, EDAX Inc., Abingdon, UK), EBSD maps were obtained by using HKL Channel 5. 


\section{Results and Discussion}

\subsection{Original Microstructure}

Figure 1 shows the EBSD orientation map of the Al-Cu-Li-Mg-Ag alloy after homogenization. The grain size is about $190 \mu \mathrm{m}$. In the map, the high angle grain boundaries (HAGBs) are depicted in black lines whereas the low angle grain boundaries (LAGBs) are depicted in white lines. HAGBs and LAGBs are differentiated by the misorientation angle, HAGBs are defined as boundaries with misorientation angles higher than $15^{\circ}$, while LAGBs are defined as misorientation angles lower than $15^{\circ}$. As shown in Figure 1b, HAGBs occupy about $70 \%$ of the boundaries and the average misorientation angle is around $30^{\circ}$, so the majority of grain boundaries in the starting material are HAGBs.
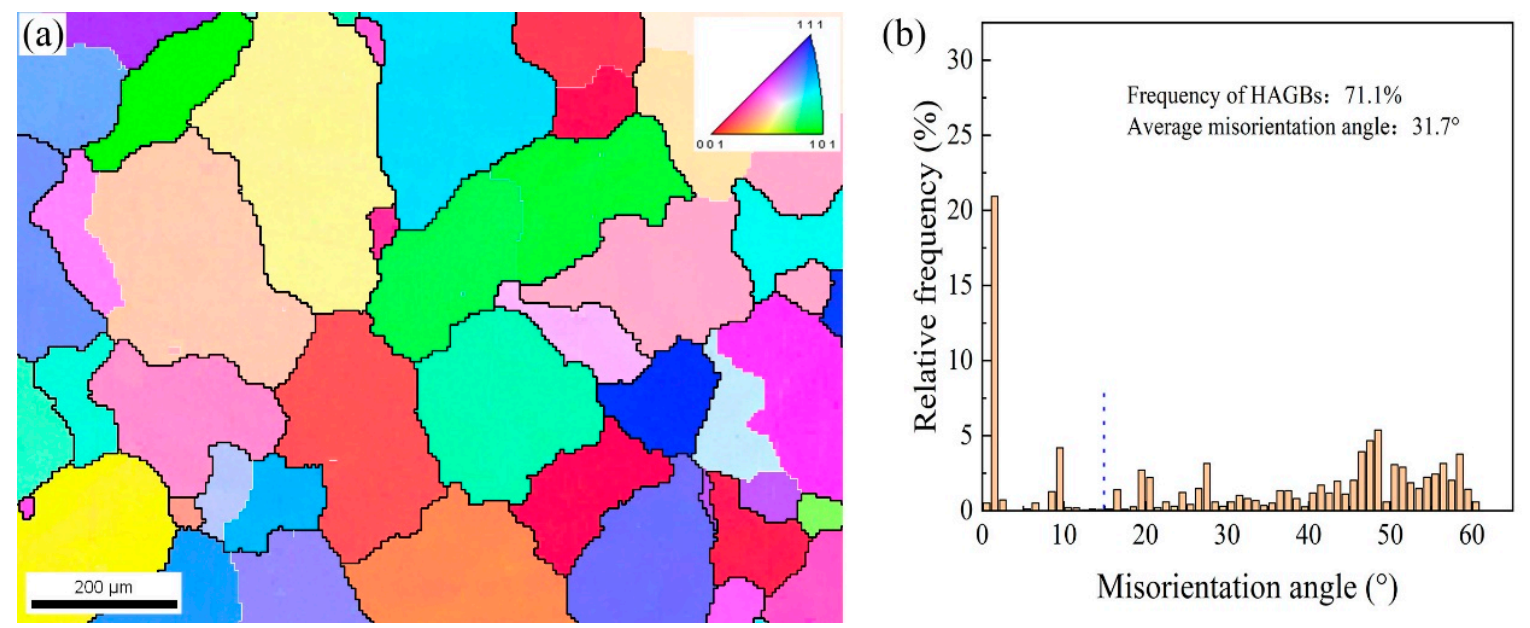

Figure 1. (a) Electron back-scattered diffraction (EBSD) map and (b) grain boundary misorientation angle of homogenized Al-Cu-Li-Mg-Ag alloy.

\subsection{Flow Behavior}

Figure 2 shows the true stress-true strain curves of the Al-Cu-Li-Mg-Ag alloy during hot compression. In all compression tests, the flow stress decreases progressively with the increase of strain after a peak stress. This is dynamic softening, which is a result of dynamic recovery and recrystallization [16]. At a given strain rate, the flow stress decreases with increasing deformation temperatures, because of a higher softening effect at higher temperatures, and lower resistance to the motion of dislocations. When the sample is compressed at the same temperature, the peak stress decreases with the decreasing strain rates, as a low strain rate extends the deformation time and offers more time for dynamic softening [17]. However, adiabatic heating due to rapid plastic deformation will lead to the flow softening, especially at higher strain rates [18]. Because of this effect, the corrected flow stress shown in Figure 2c,d has been applied to the data used in following sections. 

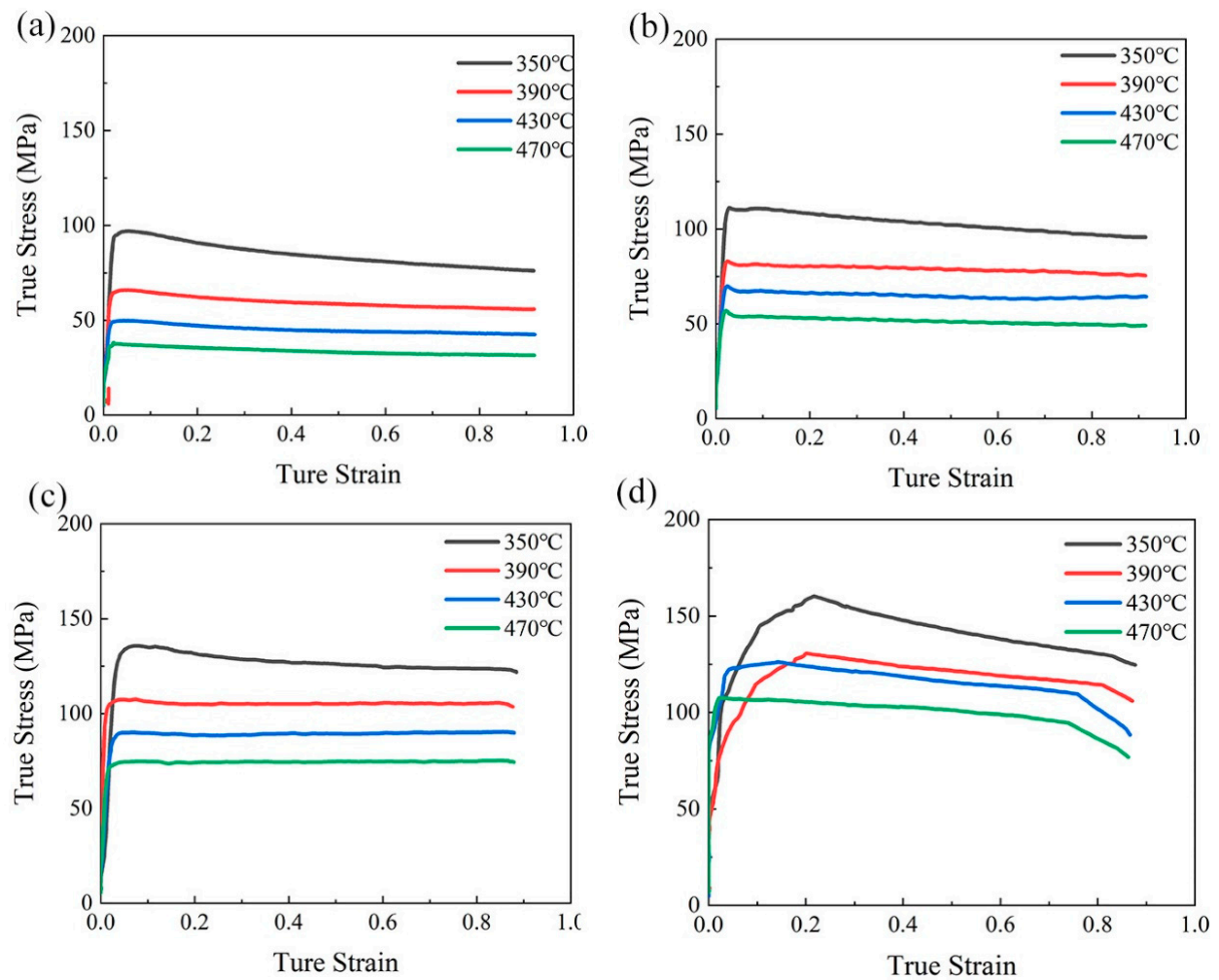

Figure 2. True stress-true strain curves of the Al-Cu-Li-Mg-Ag alloy at various strain rates: (a) $0.01 \mathrm{~s}^{-1}$; (b) $0.1 \mathrm{~s}^{-1} ;$ (c) $1 \mathrm{~s}^{-1} ;$ (d) $10 \mathrm{~s}^{-1}$.

\subsection{Constitutive Equation}

The constitutive equation for Al-Cu-Li-Mg-Ag alloy can be developed from the experimental strain-stress curves in Figure 2. In order to understand the influence of deformation temperature and strain rate on the experimental strain-stress curve, the Zener-Hollomon parameter $\mathrm{Z}$ is often used [8]:

$$
\mathrm{Z}=\dot{\varepsilon} \exp (\mathrm{Q} / \mathrm{RT})
$$

where $\dot{\varepsilon}$ represents the strain rate, $Q$ is the activation energy of hot deformation $(\mathrm{kJ} / \mathrm{mol}), \mathrm{R}$ is the universal gas constant $\left(8.314 \mathrm{~kJ} \mathrm{~mol}^{-1}\right)$, and $\mathrm{T}$ is the deformation temperature. The $\mathrm{Z}$ parameter is an important parameter for hot deformation, especially in understanding the microstructure evolution during hot deformation [19].

The relation among stress, strain rate, and temperature during hot deformation can also be expressed by [2]:

$$
\dot{\varepsilon}=\mathrm{f}(\sigma) \exp (-\mathrm{Q} / \mathrm{RT})
$$

where $f(\sigma)$ is a function of stress $\sigma$ and has different expressions at different stress levels. It is generally expressed using a hyperbolic sine function, as

$$
\mathrm{f}(\sigma)=\mathrm{A}\left[\sinh (\alpha \sigma)^{\mathrm{n}}\right]
$$

where $\mathrm{A}, \alpha$, and $\mathrm{n}$ are material constants and $\alpha=\beta / n_{1} . \mathrm{n}_{1}$ and $\beta$ can be calculated by the mean slope of $\ln \dot{\varepsilon}-\ln \sigma$ and $\ln \dot{\varepsilon}-\sigma$, respectively, so that the value of $\alpha$ can be obtained thereafter.

From Equations (1)-(3), it can be derived that the values of $Q$ and $\ln Z$ are

$$
\mathrm{Q}=\mathrm{R}\left[\frac{\partial \ln \dot{\varepsilon}}{\partial \ln [\sinh (\alpha \sigma)]}\right]_{\mathrm{T}}\left[\frac{\partial \ln [\sinh (\alpha \sigma)]}{\partial(1 / \mathrm{T})}\right]_{\dot{\varepsilon}}=\mathrm{RnS}
$$




$$
\ln \mathrm{Z}=\ln \mathrm{A}+\operatorname{nln}[\sinh (\alpha \sigma)]
$$

where $\mathrm{n}$ is defined as the relative change of $\ln \dot{\varepsilon}$ vs. $\ln [\sinh (\alpha \sigma)]$ at constant temperatures and the value of $S$ is defined as the relative change of $\ln [\sinh (\alpha \sigma)]$ vs. $1 / T$ at constant strain rates. Therefore, $\mathrm{Q}$ and $\ln Z$ can be calculated according to Equations (4) and (5) respectively.

The method to determine the material constants listed above is shown hereafter, using the strain at 0.8 as an example. As a result of linear fitting in Figure 3, the average value of $n_{1}$ and $\beta$ are 8.053 and $0.1004 \mathrm{MPa}^{-1}$, respectively. Therefore, $\alpha$ can be obtained by $\beta / \mathrm{n}_{1}$, which is $0.0125 \mathrm{MPa}^{-1} . \mathrm{n}$ is 5.886 , and $\mathrm{Q}$ is $159.9 \mathrm{~kJ} \mathrm{~mol}^{-1}$. The value of $\ln Z$ can then be figured out on the basis of Equation (1) and the results are listed in Table 1.
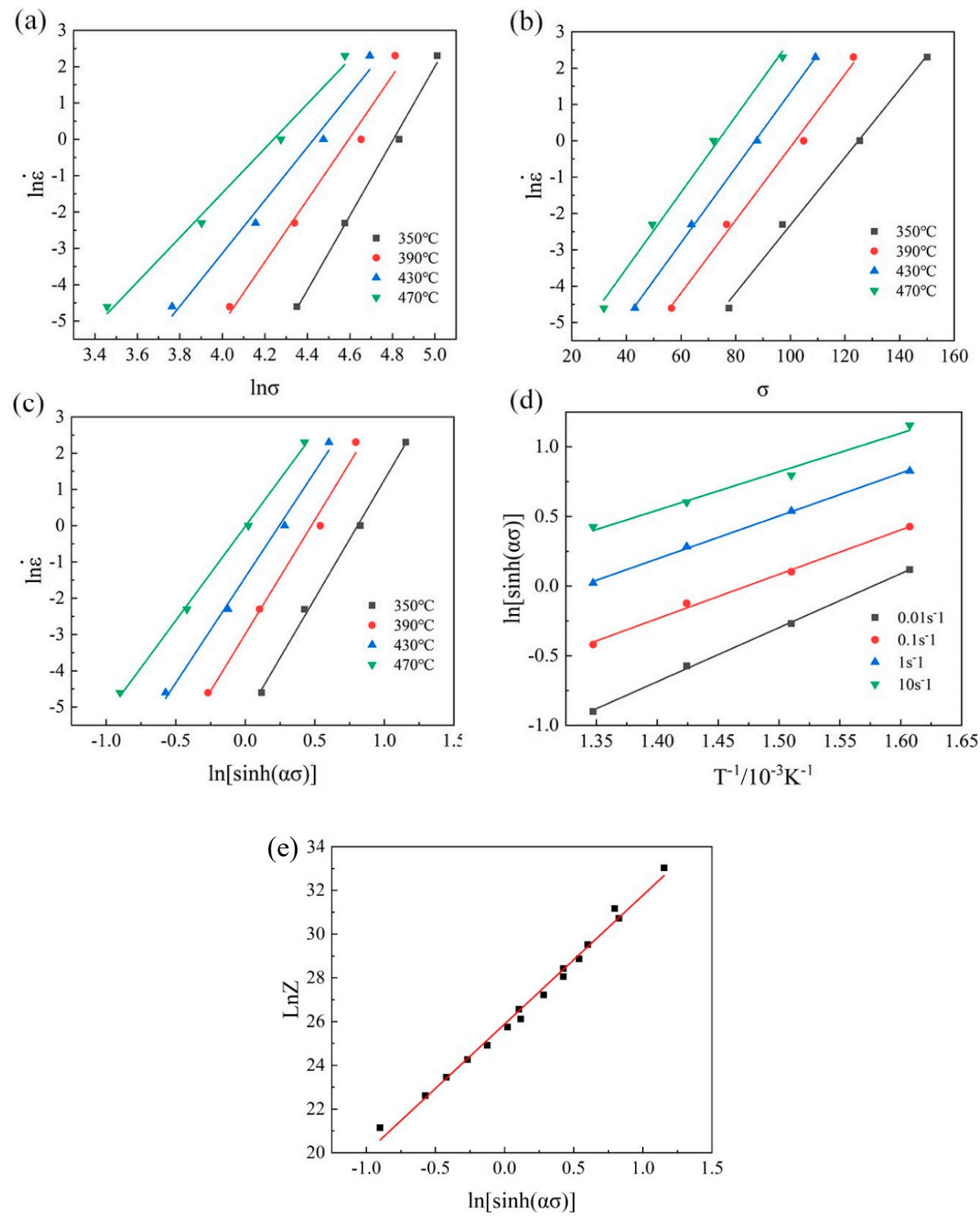

Figure 3. The (a) $\ln \dot{\varepsilon}$ vs. $\ln \sigma$, (b) $\ln \dot{\varepsilon}$ vs. $\sigma$, (c) $\ln \dot{\varepsilon}$ vs. $\ln [\sinh (\alpha \sigma)] ;$ (d) $\ln [\sinh (\alpha \sigma)]$ vs. and (e) $\ln Z$ vs. $\ln [\sinh (\alpha \sigma)]$ curves at stain of 0.8 for the experimental alloy. 
Table 1. $\ln Z$ at a strain of 0.8 for different deformation condition.

\begin{tabular}{ccccc}
\hline Strain Rate $/ \mathbf{s}^{-\mathbf{1}}$ & $\mathbf{3 5 0}{ }^{\circ} \mathbf{C}$ & $\mathbf{3 9 0}{ }^{\circ} \mathbf{C}$ & $\mathbf{4 3 0}{ }^{\circ} \mathbf{C}$ & $\mathbf{4 7 0}{ }^{\circ} \mathbf{C}$ \\
\hline 0.01 & 26.116 & 28.419 & 30.722 & 33.024 \\
0.1 & 24.261 & 26.563 & 28.866 & 31.168 \\
1 & 22.616 & 24.919 & 27.221 & 29.524 \\
10 & 21.149 & 23.452 & 25.754 & 28.057 \\
\hline
\end{tabular}

$\ln \mathrm{A}$ is the value of $\ln \mathrm{Z}$ at $\ln [\sinh (\alpha \sigma)]=0$ and can be obtained from Figure 3e. Therefore, the constitutive equation for the $\mathrm{Al}-\mathrm{Cu}-\mathrm{Li}-\mathrm{Mg}-\mathrm{Ag}$ alloy at the strain of 0.8 is:

$$
\dot{\varepsilon}=1.74 \times 10^{11}[\sinh (0.0125 \sigma)]^{5.886} \times \exp (-159.9 / \mathrm{RT})
$$

For a more general expression, different levels of strains should be considered, as it plays an important role in the flow behavior of aluminum alloy (shown in Figure 2). Based on the method of compensation for strain [20], the constitutive equation predicting flow stresses for the $\mathrm{Al}-\mathrm{Cu}-\mathrm{Li}-\mathrm{Mg}$ - $\mathrm{Ag}$ alloy can be described as:

$$
\begin{gathered}
\sigma=\frac{1}{\alpha}\left\{\left(\frac{Z}{\mathrm{~A}}\right)^{\frac{1}{n}}+\left[\left(\frac{\mathrm{Z}}{\mathrm{A}}\right)^{\frac{2}{\mathrm{n}}}+1\right]^{\frac{1}{2}}\right\} \\
\mathrm{Z}=\dot{\varepsilon} \exp \left(\frac{\mathrm{Q}}{\mathrm{RT}}\right)
\end{gathered}
$$

The material constants $(\alpha, Q, n$, and $\ln A)$ in the above equation at various strains ranging from 0.1 to 0.8 with an interval of 0.1 can be calculated in the similar method. The results are shown in Figure 4. It is clear that these constants are strain dependent and can be correlated by the seventh-order polynomial fitting curves to describe accurately the influence of strains.

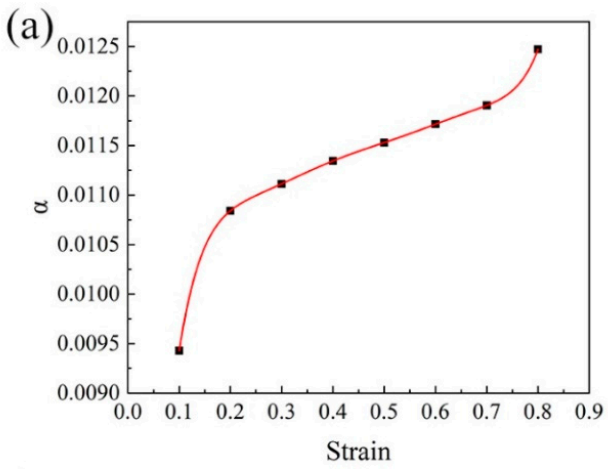

(b)

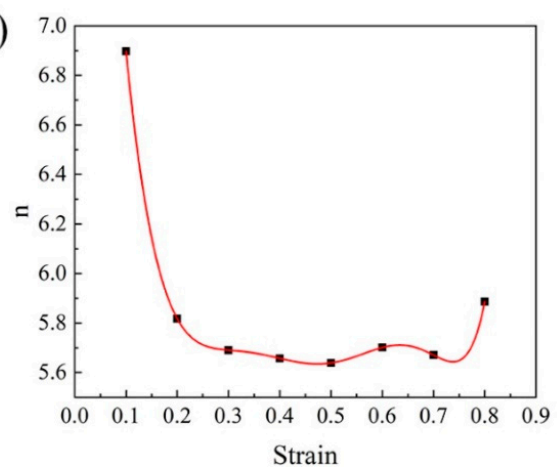

(c)

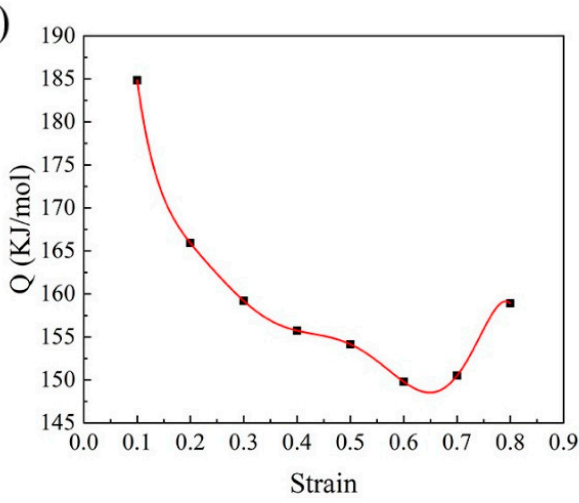

(d)

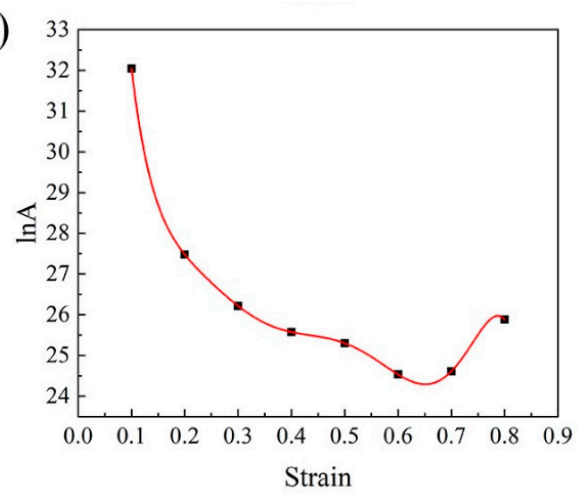

Figure 4. The dependence of material constants (a) $\alpha$; (b) n; (c) Q; (d) $\ln \mathrm{A}$ on strain. 
The predicted values of flow stresses and the experimental data are plotted in Figure 5. The correlation coefficient $(\mathrm{R})$ can be introduced to evaluate the accuracy of the constitutive equations. By fitting the predicted data with the experimental values of flow stresses, the value of $R$ can be figured out as 0.985 with an average relative error (AARE) of $5.4 \%$, which indicates the developed model can predict the high temperature behavior of the experimental $\mathrm{Al}-\mathrm{Cu}-\mathrm{Li}-\mathrm{Mg}-\mathrm{Ag}$ alloy very well.

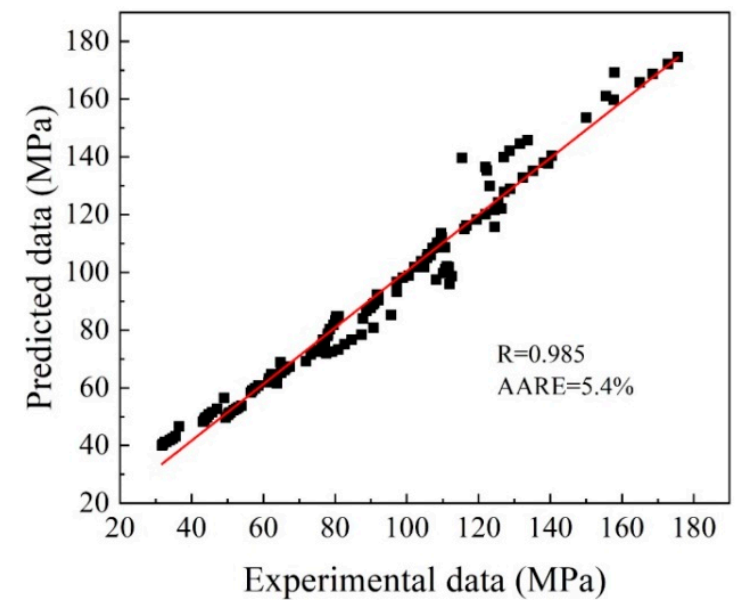

Figure 5. The predicted flow stress vs. the experimental flow stress.

\subsection{Hot Processing Map}

Hot processing maps can be generated to determine the appropriate process domains for hot working. The values of $\lg$ (true stress) versus $\lg$ (strain rate) in a compression temperature range between $350{ }^{\circ} \mathrm{C}$ and $470{ }^{\circ} \mathrm{C}$ are presented in Figure 6a, which are fitted by a cubic spline function. The values of power dissipation $(\eta)$ are calculated as a function of temperature and strain rate, which are shown as contour lines in Figure $6 \mathrm{~b}$ and can be used to assess the relationship between power dissipation capacity and microstructural evolution of materials [5]. A dimensionless parameter $\xi$ is also introduced to identify the dependence of flow instability on the temperature and strain rate, and the shaded area in the processing map indicates the unstable domain $(\xi<0$, Figure $6 b)$.

If a material is deformed within the unstable window, the material is easy to form undesirable microstructures such as adiabatic shear band and intergranular cracking. Therefore, these instability domains $(\xi<0)$ should be avoided when selecting proper parameters for hot working [21,22], while the high power dissipation areas are usually an appropriate processing zone. Based on the processing map, it can be figured out that the optimum process window for this $\mathrm{Al}-\mathrm{Cu}-\mathrm{Li}-\mathrm{Mg}$-Ag alloy locates in the domain at a temperature between $440{ }^{\circ} \mathrm{C}$ and $470{ }^{\circ} \mathrm{C}$, and a strain rate between $0.01 \mathrm{~s}^{-1}$ and $0.03 \mathrm{~s}^{-1}$. The instable domain is mainly in the window at a temperature range between $350^{\circ} \mathrm{C}$ and $430{ }^{\circ} \mathrm{C}$, and a strain rate between $1 \mathrm{~s}^{-1}$ and $10 \mathrm{~s}^{-1}$, which is larger than the aluminum alloy 2060 reported, due to greater strains applied in this work [15].

For an accuracy evaluation of processing parameters, the processing map alone is not enough, due to the prediction error of the dynamic materials model [23]. The processing map, composed of power dissipation efficiency and instability domains, connects the microstructure change and the deformation conditions $[24,25]$. Therefore, microstructure observations are also needed for the purpose of deciding the optimal hot working conditions. Therefore, the microstructures of samples compressed in different domains of the processing map, i.e., the safe domains with high power dissipation (domain A) and low power dissipation (domain B), and unstable domain (domain C) (Figure 6b), will be discussed. The deformation mechanisms will be discussed accordingly. 
(a)

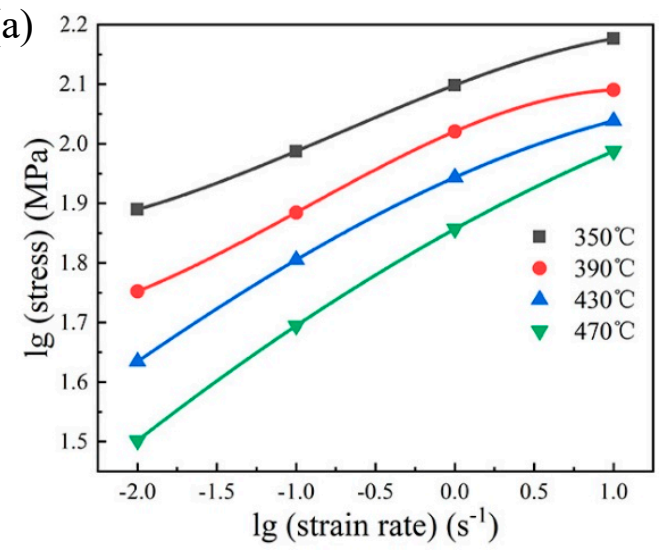

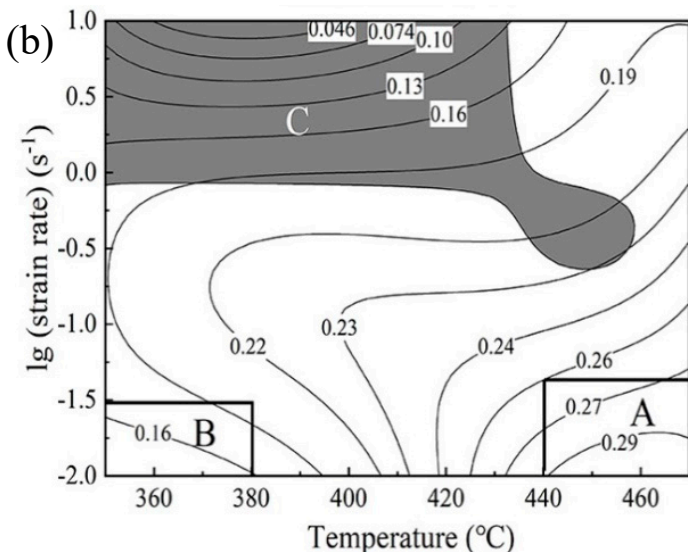

Figure 6. (a) The relationship between stress and strain rate, (b) processing map at a true strain of 0.8 .

\subsection{Microstructure Evolution}

Figure 7 shows the Zener-Hollomon parameter of the Al-Cu-Li-Mg-Ag alloy deformed at different deformation conditions with a true strain of 0.8 . It is obvious that the value of $\ln Z$ decreases with the increase of temperature and decrease of strain rate. The highest $\ln Z$ is obtained at the area with large strain rates (unstable domain $C$ ). The medium values of $\ln Z$ (around 25-27) locates at domain $B$, where both strain rates and deformation temperature are low. The lowest value of $\ln Z$ (about 22) locates in domain A, where the deformation temperature is high and the strain rate is low. The influence of deformation temperature and strain rates on microstructure changes will be discussed in the next section.

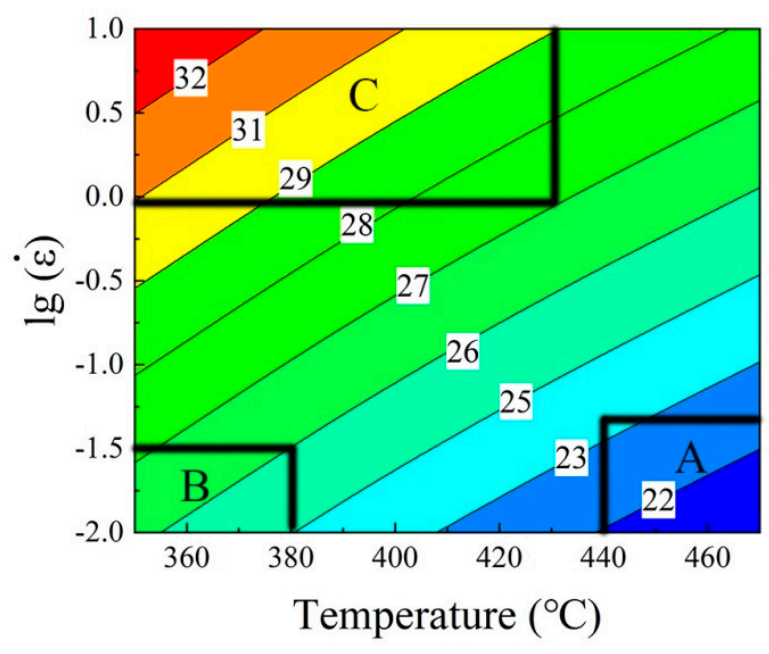

Figure 7. The Zener-Hollomon parameter of the studied alloy at different temperatures and strain rates with a true strain of 0.8 . (The values of $\ln \mathrm{Z}$ are marked on the contour lines; regions $\mathrm{A}, \mathrm{B}$, and $\mathrm{C}$ correspond the domains shown in Figure 6b).

\subsubsection{Effect of Strain Rates}

Figure 8 illustrates the effect of strain rate on the microstructure change of the studied $\mathrm{Al}-\mathrm{Cu}-\mathrm{Li}-\mathrm{Mg}-\mathrm{Ag}$ alloy deformed at $350{ }^{\circ} \mathrm{C}$. The microstructures show typical deformed and recovered structure, i.e., the grains elongate perpendicularly to the compression direction, and many sub-grain boundaries are formed inside the grains. Some recrystallized grains (marked by a black arrow in Figure $8 \mathrm{a}, \mathrm{b}$ ) are observed at lower strain rate (domain A). Adiabatic shear bands, distributed around $45^{\circ}$ away from the compression direction as indicated by black rectangles in Figure $8 \mathrm{c}$, d, are observed at higher strain rates (domain $C$ with higher $Z$ value). In this case, severe deformation heat resulted 
from high strain rates transfer inadequately within limited deformation time, which results in local flow of materials along the plane of the highest shear stress [24,25]. Cracks are expected to generate for the relief of local stress concentrations, thus deformation parameters within domain $\mathrm{C}$ are not desirable.
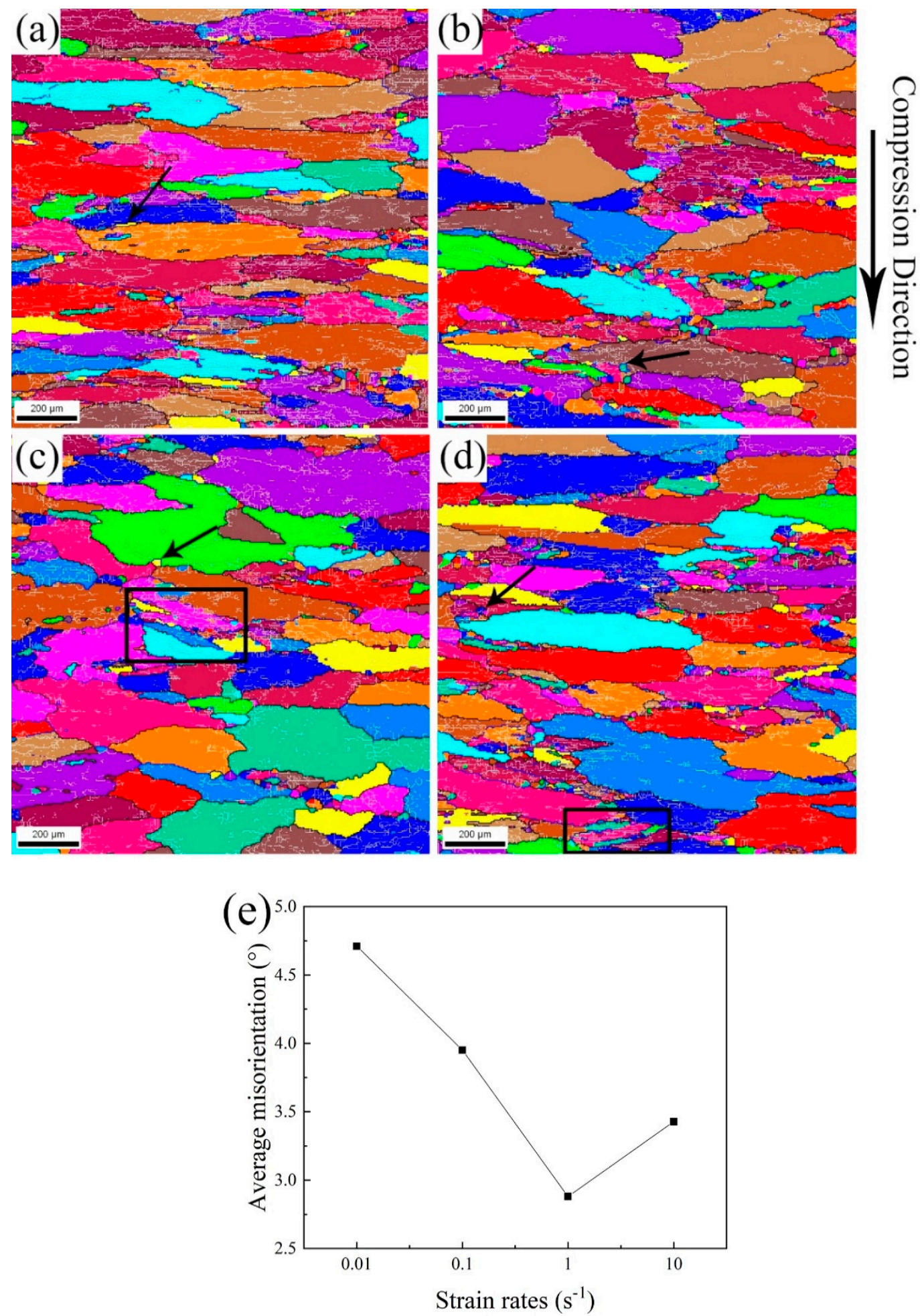

Figure 8. EBSD maps of the Al-Cu-Li-Mg-Ag alloy at $350{ }^{\circ} \mathrm{C}$ with various strain rates (a) $0.01 \mathrm{~s}^{-1}$; (b) $0.1 \mathrm{~s}^{-1}$; (c) $1 \mathrm{~s}^{-1}$; (d) $10 \mathrm{~s}^{-1}$, and (e) average misorientation angle for the four strain rate. 
The average misorientation between grains can also be calculated on the basis of EBSD technique. As shown in Figure 8e, the average misorientation decreases firstly with increasing strain rate until strain rates reach $1 \mathrm{~s}^{-1}$, and then increases. Deformation at lower strain rates generally implies that there is adequate time for the dislocation movement, which is evidenced by the massive sub-grain boundaries detected in the grain interior (white lines with misorientation lower than $15^{\circ}$ in Figure $8 \mathrm{a}-\mathrm{c}$ ). At higher strain rates (strain rates $\geq 1 \mathrm{~s}^{-1}$ ), the adiabatic heating may also be induced, which offers more energy for boundary migration. Thus, the average misorientation values show a non-linear dependence of strain rates.

\subsubsection{Effect of Deformation Temperature}

Deformation temperature, another factor of Zener-Hollomon parameter Z, has an important influence on the change of microstructures as well. Figure 9 shows the EBSD morphology of the $\mathrm{Al}-\mathrm{Cu}-\mathrm{Li}-\mathrm{Mg}-\mathrm{Ag}$ alloy deformed at $0.01 \mathrm{~s}^{-1}$ and various temperatures. When the sample is deformed at low temperature $\left(350{ }^{\circ} \mathrm{C}, \ln Z=26.1\right)$, dislocation tangling is readily generated, and then dislocation walls develop in the grain interior [5]. So, the microstructure features deformed structures (flat grains) and sub-grains within the grain, as shows in Figure 9a. With increasing temperature, the migration rate of dislocations is enhanced. When the deformation temperature increases to $470{ }^{\circ} \mathrm{C}(\ln Z=21.1)$, the improvement of grain boundary mobility promotes the nuclei and growth of recrystallized grains around the original grain boundaries. In addition, dislocation climbs are also enhanced at elevated temperatures, which promote the formation of sub-grain boundaries. Consequently, more recrystallized grains and sub-grains (indicated by white arrows) at the grain boundary and grain interiors (indicated by black arrows) are found than in other lower temperatures (Figure 9a-d). The degree of recrystallization and LAGB\% increase with increasing temperature in Figure 9e,f. The fraction of DRX is low regardless of the deformation temperature, which is consistent with the results of Ling [15], which state that the dynamic recovery is the main reason for dynamic softening.
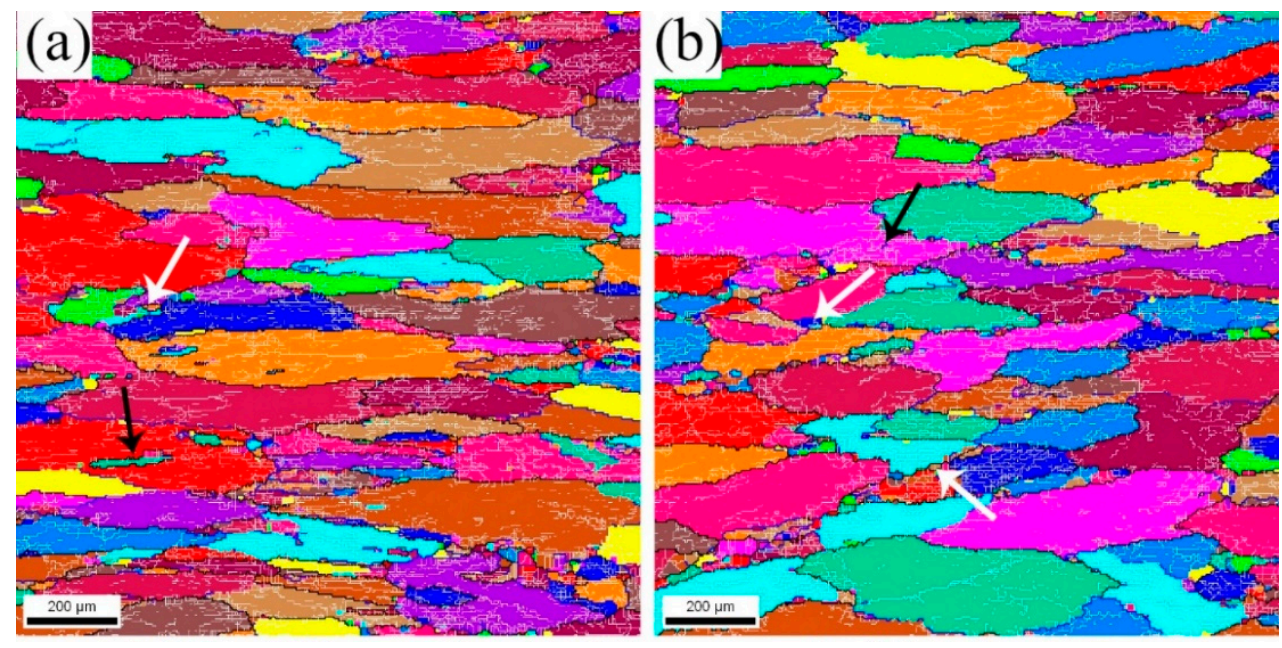

Figure 9. Cont. 

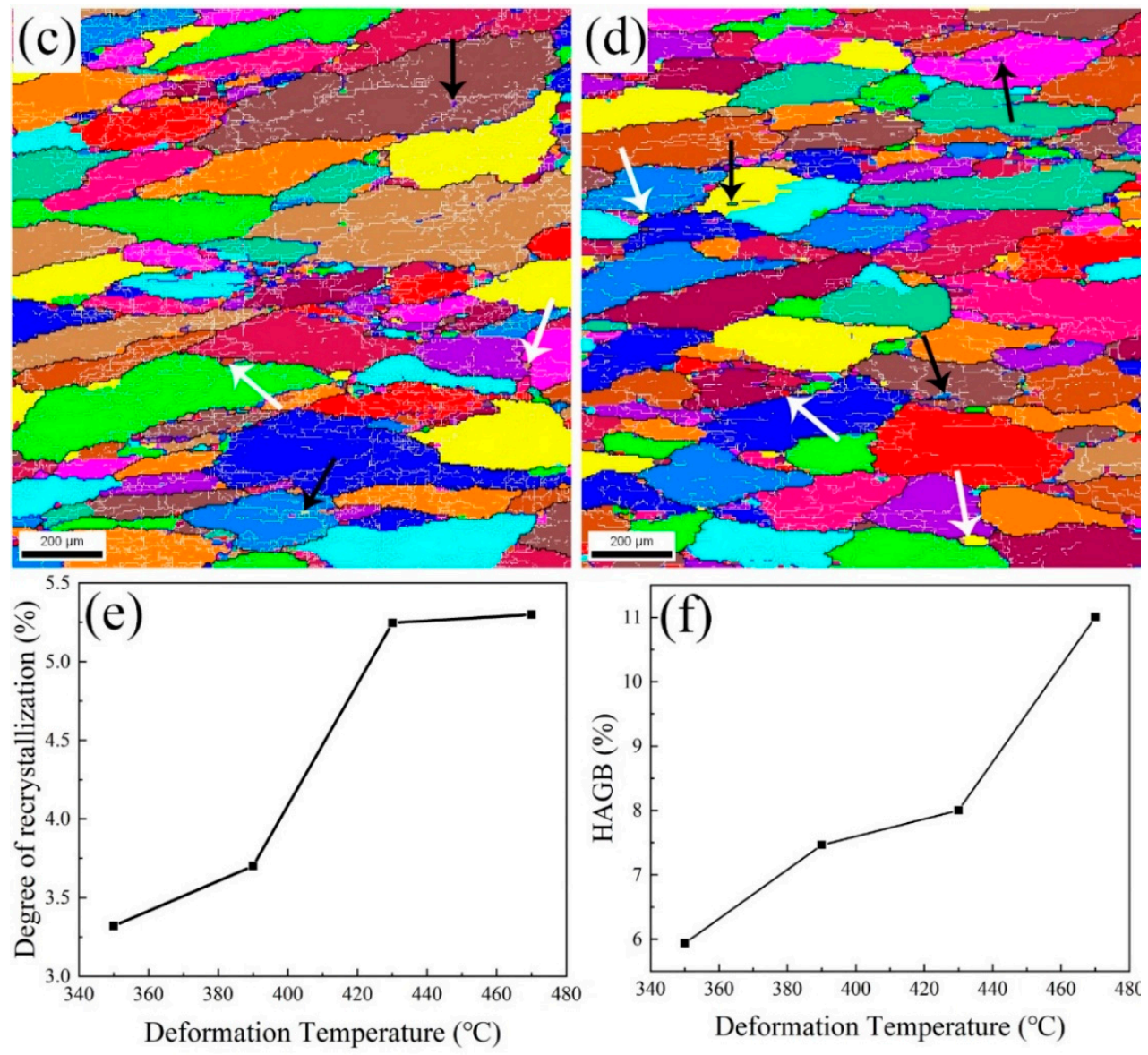

Figure 9. EBSD maps of the Al-Cu-Li-Mg-Ag alloy deformed at a strain rate of $0.01 \mathrm{~s}^{-1}$ and various temperatures (a) $350{ }^{\circ} \mathrm{C}$, (b) $390{ }^{\circ} \mathrm{C}$, (c) $430{ }^{\circ} \mathrm{C}$, (d) $470{ }^{\circ} \mathrm{C}$, (e) degree of recrystallization and (f) the frequency of HAGB.

\subsubsection{Recrystallization Mechanism}

Based on the processing map (Figure $6 \mathrm{~b}$ ) three representative domains identified by the value of $\ln Z$ are chosen to investigate the recrystallization mechanism. Domains A and B are optimum processing regions ( $\mathrm{A}$ is the highest and $\mathrm{B}$ is the lowest value of power dissipation) while domain $\mathrm{C}$ is all areas within the unstable domain boundary. Figure 10 illustrates the EBSD morphology of the alloy deformed in different domains: unstable domain C (Figure 10a,b), low power dissipation domain B (Figure 10c), and high power dissipation domain A (Figure 10d). As known to us, the continuous dynamic recrystallization (CDRX) is an important dynamic recrystallization mechanism for high stacking fault energy materials during thermo-mechanical processing. A characteristic of CDRX is the increase of average misorientation angle with the increasing strain [26]. The point-to-origin (cumulative) misorientation is obtained from Figure 10a-d in the grain with similar orientation and shown in Figure 10e. An obvious increase of misorientation gradient is observed inside the grains. Misorientation to the initial grain boundary higher than $15^{\circ}$ is observed in all samples, which is strong evidence for CDRX. The fraction of CDRX can be evaluated by the fraction of misorientation angles between $10^{\circ}$ and $15^{\circ}$ [26-29]. Figure $10 \mathrm{f}$ shows the fraction of misorientation angle between $10^{\circ}$ and $15^{\circ}$ in the four samples, which significant increases compared to the original sample and decreases with decreasing $\operatorname{lnZ}$, suggesting the fraction of CDRX decreases with decreasing $\ln Z$. 

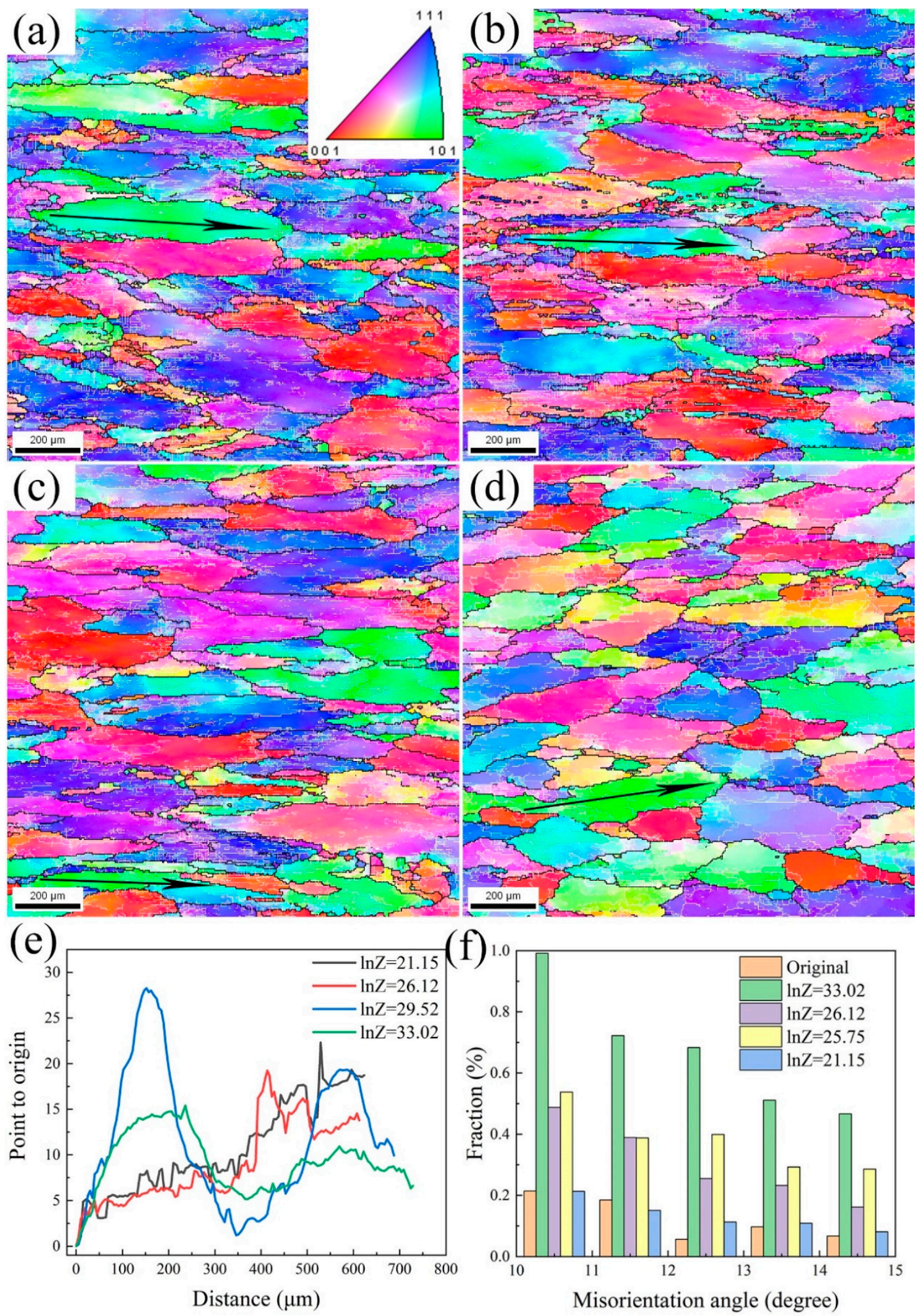

Figure 10. Inverse pole figure maps of the $\mathrm{Al}-\mathrm{Cu}-\mathrm{Li}-\mathrm{Mg}-\mathrm{Ag}$ alloy under various deformation conditions: (a) $\ln Z=21.15$; (b) $\ln Z=25.75$; (c) $\ln Z=26.12$; (d) $\ln Z=33.02$; (e) the changes of misorientation angle along the black lines in $(\mathbf{a}-\mathbf{d})$ and $(\mathbf{f})$ the proportion of HAGBs.

Another representative dynamic recrystallization mechanism is discontinuous dynamic recrystallization (DDRX). Grain boundary bulging (BLG), which shows a bow out of grain boundary, 
is a typical nucleation mechanism of DDRX [30]. The grains with BLG feature, marked by blue arrows, are observed in different deformation conditions, together with the CDRX featured grains indicated by black arrows in Figure 11. The number of grains with BLG features increases with the decreasing of $\operatorname{lnZ}$. Lower values of $\ln Z$ usually occur at higher deformation temperatures or lower strain rates, in which case the sub-grain size increases and the dislocation density decreases. Therefore, it can be deduced that the main recrystallization mechanism is gradually transformed from CDRX to DDRX with the decreasing value of $\ln Z$.

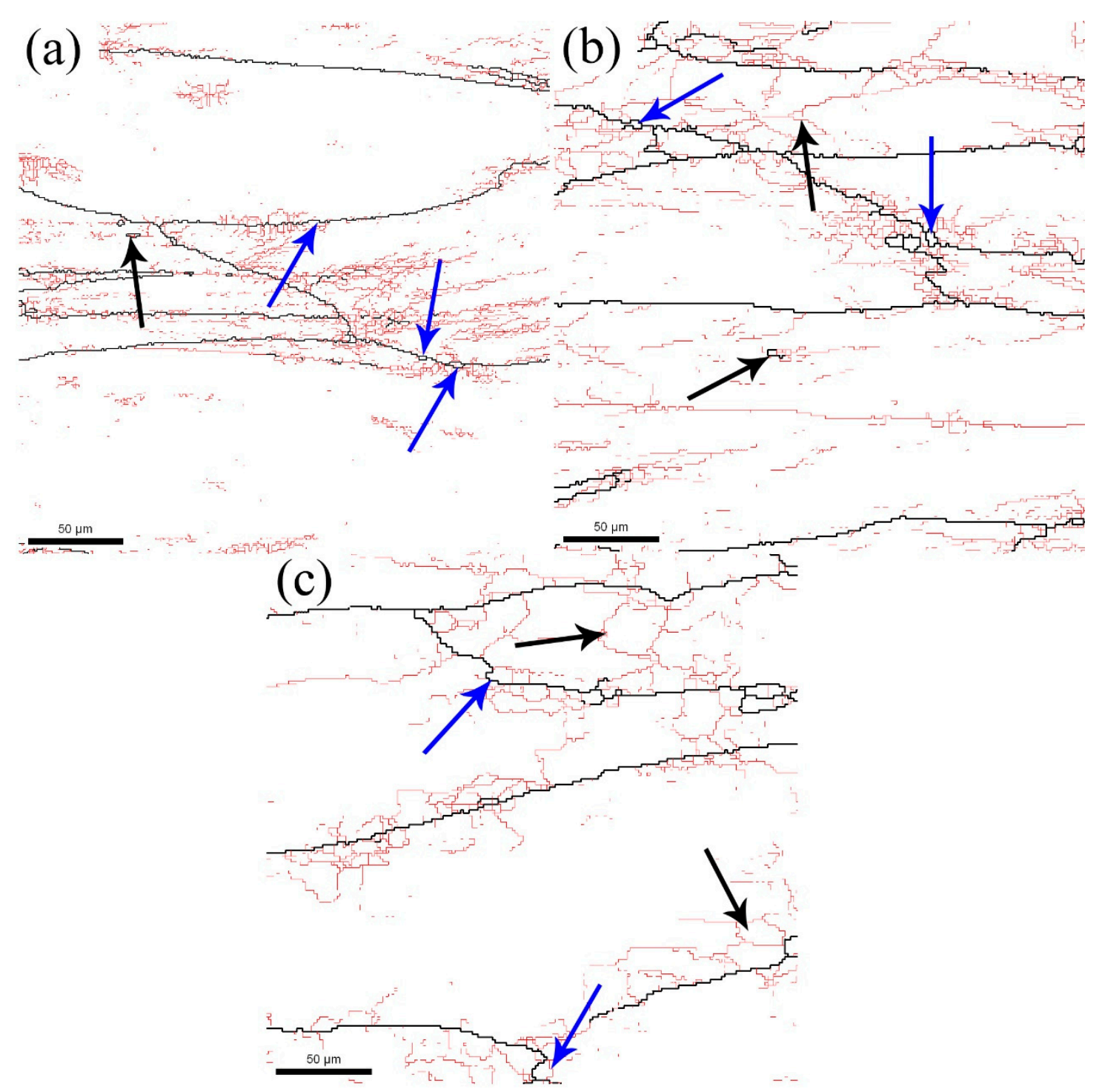

Figure 11. Grain boundary maps of the Al-Cu-Li-Mg-Ag alloy under various $\ln Z$ : (a) $\ln Z=21.15$; (b) $\ln Z=26.12 ;(\mathbf{c}) \ln Z=33.02$.

Quite a few insoluble constituent particles exist in the $\mathrm{Al}$ alloys after homogenization treatments. Most of these insoluble particles are crushed by external force during hot processing and distributed along the processing direction [31]. These particles have a complicated effect on the microstructure evolution during hot processing. On one side, these particles may promote the recrystallization by particle stimulated nucleation. On the other hand, they may inhibit recrystallization by hindering the motion of the grain boundary. The influence of hot deformation parameters on the constituent particles is important and should have significant influence on the microstructure evolution during hot deformation, and should be clarified in the future. 


\section{Conclusions}

In this work, an $\mathrm{Al}-\mathrm{Cu}-\mathrm{Li}-\mathrm{Mg}-\mathrm{Ag}$ alloy was deformed in a temperature range of $350-470{ }^{\circ} \mathrm{C}$ and a strain rate range of $0.01-10 \mathrm{~s}^{-1}$. The flow behavior and microstructure evolution were carefully studied. The conclusions are presented below.

(1) A constitutive equation was developed based on the experimental true stress-strain curves, and for the alloy deformed at a strain of 0.8 it was expressed as

$$
\dot{\varepsilon}=1.74 \times 10^{11}[\sinh (0.0125 \sigma)]^{5.886} \times \exp [-159.9 / R T]
$$

(2) The hot processing map was established and the optimum process window was located in the domain with a temperature between $440{ }^{\circ} \mathrm{C}$ and $470{ }^{\circ} \mathrm{C}$, and a strain rate between $0.01 \mathrm{~s}^{-1}$ and $0.03 \mathrm{~s}^{-1}$.

(3) Dynamic recovery was the main softening mechanism for the experimental alloy. Dynamic recrystallization was also observed, and CDRX was the main recrystallization mechanism at higher $\ln Z$ while DDRX was the main recrystallization mechanism at lower lnZ.

Author Contributions: X.W. and L.C. formulated the experimental design; B.L. and C.L. carried out the Gleeble tests and the microstructure characterization; B.L. analyzed the experimental data and wrote the original draft; X.W. and N.C. discussed the results and made the revisions; L.C. and G.H. applied for the financial support. All authors have read and agreed to the published version of the manuscript.

Funding: The authors acknowledge the financial support by the National Natural Science Foundation of China (51871033, 51421001); the National Defense Basic Scientific Research Program; Key Research and Development Program of China (2016YFB0700403); Venture \& Innovation Support Program for Chongqing Overseas Returnees (cx2018002); the Fundamental Research Funds for the Central Universities (2020CDJDCL001); the Open Funding of International Joint Laboratory for Light Alloys (MOE), Chongqing University. X.W. thanks the support of the "111" Project (B16007) by the Ministry of Education and the State Administration of Foreign Experts Affairs of China.

Conflicts of Interest: The authors declare no conflict of interest.

\section{References}

1. Alexopoulos, N.D.; Migklis, E.; Stylianos, A.; Myriounis, D.P. Fatigue behavior of the aeronautical Al-Li (2198) aluminum alloy under constant amplitude loading. Int. J. Fatigue 2013, 56, 95-105. [CrossRef]

2. Li, B.; Pan, Q.; Yin, Z. Characterization of hot deformation behavior of as-homogenized Al-Cu-Li-Sc-Zr alloy using processing maps. Mater. Sci. Eng. A 2014, 614, 199-206. [CrossRef]

3. Yu, X.X.; Zhang, Y.R.; Yin, D.F.; Yu, Z.M.; Li, S.F. Characterization of hot deformation behavior of a novel Al-Cu-Li alloy using processing maps. Acta Metall. Sin. 2015, 28, 817-825. [CrossRef]

4. Rioja, R.J.; Liu, J. The evolution of Al-Li base products for aerospace and space applications. Metall. Mater Trans A 2012, 43, 3325-3337. [CrossRef]

5. Liao, B.; Cao, L.F.; Wu, X.D.; Zou, Y.; Huang, G.J.; Rometsch, P.A.; Couper, M.J.; Liu, Q. Effect of heat treatment condition on the flow behavior and recrystallization mechanisms of aluminum alloy 7055. Materials 2019, 12, 311. [CrossRef]

6. Zheng, X.; Luo, P.; Chu, Z.; Xu, J.; Wang, F. Plastic flow behavior and microstructure characteristics of light-weight 2060 Al-Li alloy. Mater. Sci. Eng. A 2018, 736, 465-471. [CrossRef]

7. Yu, W.; Li, H.; Du, R.; You, W.; Zhao, M.; Wang, Z.A. Characteristic constitution model and microstructure of an Al-3.5Cu-1.5Li alloy subjected to thermal deformation. Mater. Charact. 2018, 145, 53-64. [CrossRef]

8. Zhao, Q.; Chen, W.; Lin, J.; Huang, S.S.; Xia, X.S. Hot deformation behavior of 7A04 aluminum alloy at elevated temperature: Constitutive modeling and verification. Int. J. Mater. Form. 2019, 13, $293-302$.

9. Chen, L.; Zhao, G.; Yu, J.; Zhang, W. Constitutive analysis of homogenized 7005 aluminum alloy at evaluated temperature for extrusion process. Mater. Des. 2015, 66, 129-136. [CrossRef]

10. Li, J.; Li, F.; Cai, J.; Wang, R.; Yuan, Z.; Xue, F. Flow behavior modeling of the 7050 aluminum alloy at elevated temperatures considering the compensation of strain. Mater. Des. 2012, 42, 369-377. [CrossRef] 
11. Liu, Y.; Geng, C.; Lin, Q.; Xiao, Y.; Xu, J.; Kang, W. Study on hot deformation behavior and intrinsic workability of 6063 aluminum alloys using 3D processing map. J. Alloys Compd. 2017, 713, 212-221. [CrossRef]

12. Yin, H.; Li, H.; Su, X.; Huang, D. Processing maps and microstructural evolution of isothermal compressed Al-Cu-Li alloy. Mater. Sci. Eng. A 2013, 586, 115-122. [CrossRef]

13. Shen, B.; Deng, L.; Wang, X. A new dynamic recrystallisation model of an extruded Al-Cu-Li alloy during high-temperature deformation. Mater. Sci. Eng. A 2015, 625, 288-295. [CrossRef]

14. Nayan, N.; Murty, S.V.S.N.; Chhangani, S.; Prakash, A.; Prasad, M.J.N.V.; Samajdar, I. Effect of temperature and strain rate on hot deformation behavior and microstructure of Al-Cu-Li alloy. J. Alloys Compd. 2017, 723, 548-558. [CrossRef]

15. Ou, L.; Zheng, Z.; Nie, Y.; Jian, H. Hot deformation behavior of 2060 alloy. J. Alloys Compd. 2015, 648, 681-689. [CrossRef]

16. Zhang, C.S.; Wang, C.X.; Guo, R.; Zhao, G.Q.; Chen, L.; Sun, W.C.; Wang, X.B. Investigation of dynamic recrystallization and modelling of microstructure evolution of an $\mathrm{Al}-\mathrm{Mg}-\mathrm{Si}$ aluminum alloy during high-temperature deformation. J. Alloys Compd. 2019, 773, 59-70. [CrossRef]

17. Zhao, J.; Deng, Y.; Tang, J.; Zhang, J. Influence of strain rate on hot deformation behavior and recrystallization behavior under isothermal compression of Al-Zn-Mg-Cu alloy. J. Alloys Compd. 2019, 809, 151788. [CrossRef]

18. Liu, L.; Wu, Y.; Gong, H.; Dong, F.; Ahmad, A.S. Modified kinetic model for describing continuous dynamic recrystallization behavior of Al 2219 alloy during hot deformation process. J. Alloys Compd. 2020, 817, 153301. [CrossRef]

19. Liu, S.H.; Pan, Q.L.; Li, H.; Huang, Z.Q.; Li, K.; He, X.; Li, X.Y. Characterization of hot deformation behavior and constitutive modelling of Al-Mg-Si-Mn-Cr alloy. J. Mater. Sci. 2019, 54, 4366-4383. [CrossRef]

20. Xiang, Y.; Xiao, S.; Tang, Z.; Zhou, Y. The flow behavior of homogenizated Al-Mg-Si-La aluminum alloy during hot deformation. Mater. Res. Express 2019, 6, 066563. [CrossRef]

21. Wang, Y.; Zhao, G.; Xu, X.; Chen, X.; Zhang, C. Constitutive modeling, processing map establishment and microstructure analysis of spray deposited Al-Cu-Li alloy 2195. J. Alloys Compd. 2019, 779, 735-751. [CrossRef]

22. Hu, H.E.; Wang, X.Y.; Deng, L. High temperature deformation behavior and optimal hot processing parameters of Al-Si eutectic alloy. Mater. Sci. Eng. A 2013, 576, 45-51. [CrossRef]

23. Jenab, A.; Karimi Taheri, A. Experimental investigation of the hot deformation behavior of AA7075: Development and comparison of flow localization parameter and dynamic material model processing maps. Int. J. Mech. Sci. 2014, 78, 97-105. [CrossRef]

24. Zhang, F.; Sun, J.L.; Shen, J.; Yan, X.D.; Chen, J. Flow behavior and processing maps of 2099 alloy. Mater. Sci. Eng. A 2014, 613, 141-147. [CrossRef]

25. Kai, X.; Chen, C.; Sun, X.; Wang, C.; Zhao, Y. Hot deformation behavior and optimization of processing parameters of a typical high-strength Al-Mg-Si alloy. Mater. Des. 2016, 90, 1151-1158. [CrossRef]

26. Huang, K.; Logé, R.E. A review of dynamic recrystallization phenomena in metallic materials. Mater. Des. 2016, 111, 548-574. [CrossRef]

27. Chamanfar, A.; Alamoudi, T.M.; Nanninga, E.N.; Misiolek, Z.W. Analysis of flow stress and microstructure during hot compression of 6099 aluminum alloy (AA6099). Mater. Sci. Eng. A 2019, 743, 684-696. [CrossRef]

28. Mandal, S.; Bhaduri, A.K.; Sarma, V.S. A study on microstructural evolution and dynamic recrystallization during isothermal deformation of a Ti-modified austenitic stainless steel. Metall. Mater. Trans. A 2010, 42, 1062-1072. [CrossRef]

29. Liao, B.; Wu, X.D.; Cao, L.F.; Huang, G.J.; Wang, Z.A.; Liu, Q. The microstructural evolution of aluminum alloy 7055 manufactured by hot thermo-mechanical process. J. Alloys Compd. 2019, 796, 103-110. [CrossRef]

30. Shimizu, I. Theories and applicability of grain size piezometers: The role of dynamic recrystallization mechanisms. J. Struct. Geol. 2008, 30, 899-917. [CrossRef]

31. Mcqueen, H.J.; Spigarelli, S.; Kastner, M.E.; Evangelista, E. Hot Deformation and Processing of Aluminum Alloys; CRC Press: Boca Raton, FL, USA, 2011.

(C) 2020 by the authors. Licensee MDPI, Basel, Switzerland. This article is an open access article distributed under the terms and conditions of the Creative Commons Attribution (CC BY) license (http://creativecommons.org/licenses/by/4.0/). 